\title{
FOOD SENSITIVITY AND THE NERVOUS SYSTEM: HYPERACTIVITY, ADDICTION AND CRIMINAL BEHAVIOUR
}

\section{JANINE ROBINSON AND ANNE FERGUSON}

Department of Medicine (Western General Hospital), University of Edinburgh,

Edinburgh EH4 2XU

\section{CONTENTS}

INTRODUCTION: AIMS AND SCOPE OF REVIEW

HYPERKINETIC DISORDERS: DEFINITION, PREVALENCE AND

PROGNOSIS

DEFINITION

DIAGNOSTIC CRITERIA AND SEVERITY GRADING - CONNERS' BEHAVIOUR

PROBLEM CHECKLIST.

PREVALENCE .

PROGNOSIS

THEORIES OF AETIOLOGY OF HYPERKINETIC DISORDERS, AND

HYPOTHESIS OF A FOOD-BEHAVIOUR LINK . . . . . . . . . 207

EARLY DESCRIPTIVE REPORTS . . . . . . . . . . . . . . . 208

THE FEINGOLD HYPOTHESIS. . . . . . . . . . . . . . . . . . 208

OTHER THEORIES LINKING HYPERKINETIC DISORDERS AND NUTRITION · 208

Food sensitivity .

Essential fatty acids . . . . . . . . . . . . . . . . . . . . 209

GENETICS AND HYPERKINETIC DISORDERS . . . . . . . . . . 209

TECHNIQUES AND APPROACHES - A CRITICAL ANALYSIS . . . 209

ANALYSES OF REQUIRED METHODOLOGY . . . . . . . . . . 210

THE RANGE OF METHODS USED IN THE STUDY OF BEHAVIOUR AND FOODS 211

Case mix . . . . . . . . . . . . . . . . . . . . . . . 211

Types of elimination diet . . . . . . . . . . . . . . . . 211

Approaches to the use of challenges . . . . . . . . . . . . . . $\quad . \quad 212$

STUDIES AND TRIALS OF DIET AND HYPERKINETIC DISORDERS . 212

STUDIES BASED ON OBSERVATION . . . . . . . . . . . . . 212

KEY WORK OF CONNERS

RECENT STUDIES WITH MODERN TECHNIQUES . . . . . . . . 213

FOOD ADDICTION. . . . . . . . . . . . . . . . . . . . . . 215

TOLERANCE, DEPENDENCE AND ADDICTION . . . . . . . . . 215

THE EXAMPLE OF CAFFEINE . . . . . . . . . . . . . . . 216

THE POSTULATED PHENOMENON OF FOOD ADDICTION . . . . . . 216

CARBOHYDRATE CRAVING . . . . . . . . . . . . . . . . . 216

CHOCOHOLICS. . . . . . . . . . . . . . . . . 217 
SACCHAROPHOBIA, HYPOGLYCAEMIA AND CRIMINAL

BEHAVIOUR. . . . . . . . . . . . . . . 217

DEFINITION .

CLAIMS FOR A LINK BETWEEN HYPOGLYCAEMIA, BEHAVIOUR DISORDERS

AND PSYCHIATRIC DISEASE . . . . . . . . . . . . 217

CRIMINAL BEHAVIOUR, SUGAR AND HYPOGLYCAEMIA . . . . . . 218

USE OF DIETARY CHANGES IN CRIMINAL INSTITUTIONS . . . . . . 218

EXTENSION OF THEORIES OF FOOD-CRIMINAL LINK TO OTHER FOODS . 218

ANTHROPOLOGICAL STUDIES . . . . . . . . . . . . . . 219

RECENT CRITICISMS OF THE CONCEPT OF REACTIVE HYPOGLYCAEMIA . 219

CONCLUSIONS AND RECOMMENDATIONS . . . . . . . . . . 219

BIBLIOGRAPHY ON FOOD AND THE BRAIN . . . . . . . . . 221

REFERENCES . . . . . . . . . . . . . . . . . . . . . 221

\section{INTRODUCTION: AIMS AND SCOPE OF REVIEW}

In recent years there has been considerable interest in behaviour disorders, particularly hyperactivity. Suggested causes of these conditions include hypoglycaemia, brain injury, parenting, psychosocial stress, food sensitivity, metabolic aberrations and allergy. Treatment options currently include behaviour modification, stimulant medication, educational changes and dietary management.

Some psychologists claim that their clients diagnosed as hyperactive improve on an additive-free diet. Clinical ecologists describe people who are 'allergic' to virtually all substances in foods and the environment and who may express this as abnormal behaviour with apparent addiction to the damaging substances. There are legal implications of the propounded theories that foods affect behaviour, since criminal activities have been attributed in courts as being an expression of food allergy.

Most of the literature on food--behaviour links is based on anecdotal evidence - doctors and dieticians claiming that their patients recover on a defined diet and relapse when the offending foods are reintroduced. Critical analysis shows methodological flaws in many of these studies, but also many deficiencies in controlled clinical trials which have failed to confirm open observations. Reviews in the literature often reveal prejudices of the authors for or against an association between food and behaviour.

In this review we describe the development of theories concerning links between diet and behaviour, discuss the methods employed by allergists and psychologists to examine these theories, and desciibe and analyse recent literature on the subject. We conclude that there is indeed scientifically sound evidence to support an association between foods and abnormal behaviour in children. However, the frequency of this is less than that claimed by some psychologists, psychiatrists and allergists.

\section{HYPERKINETIC DISORDERS: DEFINITION, PREVALENCE AND PROGNOSIS}

\section{DEFINITION}

According to the International Classification of Diseases, 10th revision, there is a group of hyperkinetic disorders of early onset, characterized by overactive, poorly modulated behaviour, marked inattention, and lack of persistent task involvement. Pervasiveness (extending to more than one environment) and persistence of these characteristics are 
Table 1. Recent and historical descriptions of hyperkinetic behaviour disorders

\begin{tabular}{ll}
\hline $\begin{array}{l}\text { WHO (ICD-10, Rev. 4) (1990): } \\
\text { Hyperkinetic syndrome of childhood }\end{array}$ & $\begin{array}{l}\text { Shannon, 1922: } \\
\text { Tension syndrome }\end{array}$ \\
\hline $\begin{array}{ll}\text { Short attention span } \\
\text { Distractibility }\end{array}$ & Two extremes: \\
Overactivity & Hyperkinesis \\
Underactivity & Restlessness \\
Disinhibition & Emotional instability \\
Impulsiveness & Fretfulness \\
Mood change & Highly strung \\
Aggression & Fatigue \\
Delays in skill development & Tired \\
Poor relationships & Torpid \\
& Listless \\
& Sluggish \\
& Appearing retarded \\
\hline \hline
\end{tabular}

definitive (Table 1). 'Cardinal features are impaired attention and overactivity. Both are necessary for the diagnosis' (World Health Organization, 1990).

Subdivisions of F90, Hyperkinetic disorders, are:

F90.0. Simple disturbance of activity and attention (which includes attention deficit disorder or syndrome with hyperactivity; attention deficit hyperactivity disorder).

F90.1. Hyperkinetic conduct disorder (when overall criteria for both hyperkinetic disorder, F90 and the criteria for conduct disorder, F91, are met). Conduct disorders are characterized by a repetitive and persistent pattern of dissocial, aggressive or defiant conduct.

Generally, the hyperkinetic disorders arise within the first 5 years of life. For diagnosis, behaviour problems should be of long duration, and in preschool children only extreme levels of hyperactivity should lead to the diagnosis. Main features include lack of persistence in those activities which require cognitive involvement, moving from one unfinished activity to another, and excessive, disorganized, ill-regulated activity. The children are often also reckless, impulsive, accident-prone, socially disinhibited, unpopular with peers and isolated. There may be cognitive impairment with delays in motor and language development. Low self-esteem and dissocial behaviour could be secondary complications causing an overlap between hyperkinesis and other disruptive behavioural patterns such as 'unsocialised conduct disorder'.

Males seem several times more likely to develop hyperkinetic disorders than females. Reading problems and other scholastic difficulties are common. Associated features (although unnecessary for diagnosis) include disinhibition in social relationships, recklessness in dangerous situations, impulsive flouting of social rules, learning disorders and motor clumsiness.

Much research in the hyperkinetic disorders has been undertaken in the USA, and it should be pointed out that definitions, terminology and diagnostic criteria applied in North America differ from those applied in Europe (Prendergast et al. 1988). This is almost certainly the reason why the prevalence in the USA is generally taken to be about $3 \%$ of children, whereas in Europe a figure closer to $0.1 \%$ is generally agreed.

According to the official diagnostic manual of the American Psychiatric Association, the Diagnostic and Statistical Manual of Mental Disorders (DSM III-R; American Psychiatric Association, 1987), attention-deficit hyperactivity disorder, usually abbreviated to ADHD, 
Table 2. Symptoms graded on a 0-3 scale by parents and teachers in Conners' abbreviated rating scale (Conners et al. 1976)

\author{
1. Restless or overactive \\ 2. Excitable, impulsive \\ 3. Disturbs other children \\ 4. Fails to finish things he starts - short attention span \\ 5. Constantly fidgeting \\ 6. Inattentive, easily distracted \\ 7. Demands must be met immediately - easily frustrated \\ 8. Cries often and easily \\ 9. Mood changes quickly and drastically \\ 10. Temper outbursts, explosive and unpredictable behaviour
}

can be defined as follows: 'The essential features of this disorder are developmentally inappropriate degrees of inattention, impulsiveness and hyperactivity'.

Generally all these components show some disturbance and occur in several settings, but in some individuals behaviour would only be evident in one environment, e.g. the symptoms would worsen in situations requiring sustained attention and there would be minimal signs of the disorder in situations where there was strict control, frequent reinforcement or in a novel setting. Age specific factors are involved. In younger, preschool children the main feature is gross motor overactivity exhibited as excess running and climbing, and constantly moving from one activity to another. In older children and adolescents the main features are excessive fidgeting and restlessness, difficulties in completing tasks, and careless work.

Clinically, symptoms of other disorders are often present, such as oppositional deviant disorder, conduct disorder, specific developmental disorders, as well as functional encopresis and enuresis. Nonlocalized, 'soft' neurologic signs and motor-perceptual dysfunctions (poor eye-hand coordination) may also be present. Clinical follow-ups suggest approximately one-third of ADHD children show some signs of the disorder in adulthood. Poor outcome is associated with coexisting conduct disorder, low intelligence quotient and severe parental mental disorders.

The DSM III-R has been criticized because of the wide range of symptoms included and because pervasiveness of symptoms across various situations is not deemed essential. Leung \& Luk (1988) argued that hyperactivity is not always accompanied by attention deficit. Weiss (1986) saw ADHD as encompassing "heterogeneous groups of children who have certain core problems in common, but who differ in many other important ways". The ICD10 classification (World Health Organization, 1990) is preferred by British psychiatrists and psychologists because of the stricter and narrower definitions, supportive research findings, and the rational subdivision of hyperactive disorders according to the presence or absence of associated conduct disorder (Rutter, 1989).

\title{
DIAGNOSTIC CRITERIA AND SEVERITY GRADING -- CONNERS' BEHAVIOUR PROBLEM CHECKLIST
}

Based on ten of the most common childhood behaviour problems, Conners et al. (1976) devised a checklist (also known as ASQ, abbreviated symptom questionnaire) to be used by parents and teachers (Table 2). Individual behaviours are rated as 'not at all' (score 0 ), 'just a little' (score 1), 'pretty much' (score 2) and 'very much' (score 3). Scores are totalled with a theoretical range of 0 to 30 . According to Conners, a score of 15 or more should be 
regarded as indicative of hyperkinesis. This would also be the cutoff point for inclusion of subjects into studies with hyperactive children. This score of 15 is roughly 2 standard deviations above the mean for normals.

The Connors scale has been used in different ways in many diet-behaviour studies, at the beginning and end of the study, once or twice per week, daily, and within 3 or 4 hours of ingesting test or placebo foods. Some studies required parents and teachers to rate behaviours separately (Harley et al. 1978), and it is interesting that the correlation between parent and teacher ratings varied from study to study (Conners et al. 1976; Harley et al. 1978; Williams \& Cram, 1978). Generally, teacher ratings appear to be more reliable than those of parents.

\section{PREVALENCE}

Reports of prevalence vary greatly. Feingold (1976) saw this as a problem affecting $\sim$ five million children in the USA at any time while Rostain (1991) estimated that 2-5\% of school age children have some or other form of attention deficit disorder. On the other hand, the condition is thought to be rare in the UK, perhaps because children classified as hyperactive in other countries are likely to be labelled in the UK as having a pure conduct disorder (F91 in the ICD) (Taylor, 1986). This was clearly shown in a study of 64 British children referred because of antisocial or disruptive behaviour: laboratory and clinical scales showed that antisocial, deviant conduct and inattentive, restless activity were separate phenomena (Taylor et al. 1986).

Are there recent changes in the prevalence of behaviour disorders? Barsky (1988) holds that we now give a formal name to an already highly prevalent condition. Previously children who exhibited inattentiveness, hyperactivity and impulsivity were called antisocial or disobedient and were disciplined. Now, if such children are diagnosed as hyperactive they are not punished, but treated with medication, etc. However, Arnold (1976) criticizes the notion that the problem was always there but that more awareness has brought it to the fore. He lists possible factors for a 'real' increase in hyperactivity-increased technology, chemicals, pollution, improved obstetrical practice (hence more brain-damaged children surviving who would have died previously), refinement in food processing (additives, preservatives), changes in socio-economic structure, more permissive society (bearing in mind that hyperactive children need structured settings).

\section{PROGNOSIS}

Prognosis varies and may be influenced by whether the disorder in a child is associated with conduct disorder. Common outcomes in adolescence include antisocial behaviour, academic retardation, depression and poor self image, while in adulthood alcoholism, sociopathy, hysteria and psychosis may develop (Cantwell, 1975). However, Hechtman et al. (1976) compared hyperactives as adults to a group of matched controls and stated that "they did not show significantly more antisocial behaviour, non-medical use of drugs or serious psychiatric disturbances". Where they did differ was in their restlessness, socialization skills and sense of wellbeing.

\section{THEORIES OF AETIOLOGY OF HYPERKINETIC DISORDERS, AND HYPOTHESIS OF A FOOD-BEHAVIOUR LINK}

"Fanatics and faddists inevitably flourish in areas so intimately interwoven with human foibles and enshrouded with mystery as food and allergy" (May, 1974). 


\section{EARLY DESCRIPTIVE REPORTS}

Early reports of behavioural responses to food describe tension fatigue syndrome (Shannon, 1922; Speer, 1954) and cerebral allergy (Davison, 1950). Features and symptoms of these conditions are similar to those described above (Table 1). Although allergic reactions were thought to be the mechanism by some workers (Shannon, 1922; Speer 1954), others (Randolph 1945; Dees 1954) recognized that other factors might be relevant, and more recent theories are of a pharmacological or toxic reaction. Nevertheless, the effects of the misery of primary allergic diseases, such as eczema and asthma, on behaviour should not be ignored. Clarke (1950) conducted a survey of allergists in Canada and the USA: of 171 respondents, 95 had noticed a change in personality when patients, known to be allergic, had a provoking food reintroduced into the diet. Timid, tired children as well as quarrelsome ones became friendly and happy after treatment for allergy. He accepted the possibility that mental problems could occur as a result of the discomfort of allergic diseases.

All of these early workers used elimination diets as the basic diagnostic tool, with specific foods reintroduced into the diet under experimental conditions to confirm the diagnosis. There is evidence in their writings of thoughtful and critical appraisal of their studies. For example, Randolph (1947) recognized the 'openness' of his treatment, and that positive results may have been caused by the change in parental attitude towards the child as well as the therapeutic effect of diet.

\section{THE FEINGOLD HYPOTHESIS}

The complex background to Feingold's hypothesis re foods and behaviour is outlined in an unusual medical reference, namely the USA Congressional Record (Beall, 1973). The text of an oral presentation by Dr Feingold to a medical conference is included as a supporting statement. In this he points out the deficiencies in safety evaluation of food additives such as dyes, describes early studies by others on salicylate intolerance, the presence of natural salicylates in foods and clinical improvement of hyperactive children on a salicylate-free diet. He proposed a pharmacological rather than allergic mechanism, and described how the recent increase in dollar value of artificial flavours and soft drinks parallels the incidence of hyperactivity and learning disorders.

Later, Feingold devised a diet which excluded artificial food colours and flavours, as well as foods containing natural salicylates, and claimed that adherence to this diet led to control of behavioural disturbances in $30-50 \%$ of normal and neurologically damaged children. He recommended that, to test his hypothesis properly, large samples of wellcharacterized children should be studied longitudinally for several years (Feingold, 1976). The Feingold diet is also referred to as the K-P diet, after the Kaiser-Permanente Medical Center in California where he worked in the Department of Allergy.

\section{OTHER THEORIES LINKING HYPERKINETIC DISORDERS AND NUTRITION}

\section{Food sensitivity}

Subsequent work on food sensitivity has mainly focused on proving or disproving the Feingold hypothesis. However, more recently there has been interest in other food substances such as caffeine. 
Another input into the subject has been from individuals investigated in the clinical spectrum of classical, IgE-mediated allergic reactions to foods. These usually involve protein antigens in foods such as cows' milk, eggs, fish and peanuts. The approach used by such workers has been different from that described above. For example Franklin (1988) included an allergy questionnaire, X-rays, electroencephalogram, radioallergosorbent test for IgE antibodies and hair analyses, as well as food exclusion and challenge in his studies.

\section{Essential fatty acids}

Mitchell et al. (1987) compared 48 hyperactives and 49 controls, matched for age and sex and defined by using teacher and parent questionnaires and checklists. Serum essential fatty acid (EFA) levels were measured. Conners' parent and teacher questionnaires were completed and health status was measured by a health questionnaire. Lower serum EFA levels were found in the hyperactives compared to the controls.

\section{GENETICS AND HYPERKINETIC DISORDERS}

Silbergeld \& Anderson (1982) reviewed the evidence for a genetic basis to hyperactivity. Twin studies have shown higher concordance rates in monozygotic than in dizygotic twins, and adoption studies such as those of Cantwell (1975) indicate a high incidence of psychopathology and prior hyperactivity in natural parents of hyperactive adoptive probands, but no such incidence in non-biological parents.

\section{TECHNIQUES AND APPROACHES-A CRITICAL ANALYSIS}

The National Institutes of Health Consensus Development Panel met in January 1982, and its authoritative report was published in 1983. It reviewed the nature of hyperactivity in childhood, the 'defined diets' then being widely prescribed, the empirical evidence of benefit from dietary treatment of the disorder, and biological explanations supporting this link.

The basic 'defined diet' devised by Feingold required the avoidance of naturally occurring salicylates, artificial colours, flavours and butylated hydroxytoluene (BHT), but no other preservatives. It was noted that various modifications of this diet had been used in some dietary trials.

There was agreement that the phenomenon of food-behaviour link certainly did exist.

(a) There was a limited positive association between the use of defined diet and a decrease in hyperactivity. However, only a small proportion of children unequivocally responded.

(b) Some children also showed increases in hyperactivity when they were then given artificial food colours but not with the placebo. Again, that was a small group and there were inconsistencies between reports of teachers, parents and other observers.

(c) Clinically, some children were manageable on the diet, but hyperactive after noncompliance.

The panel made important criticisms of many diet-behaviour studies. In particular, challenge studies had not adequately addressed the role in hyperactivity of all the substances eliminated from the Feingold diet. Studies had been concentrated on dyes, not flavours or preservatives.

There was a clear need for more research on mechanisms of the observed effects, particularly pharmacokinetic studies, although it was recognized that direct toxic effects, 


\section{Table 3. Problems in the design of diet-behavioural studies}

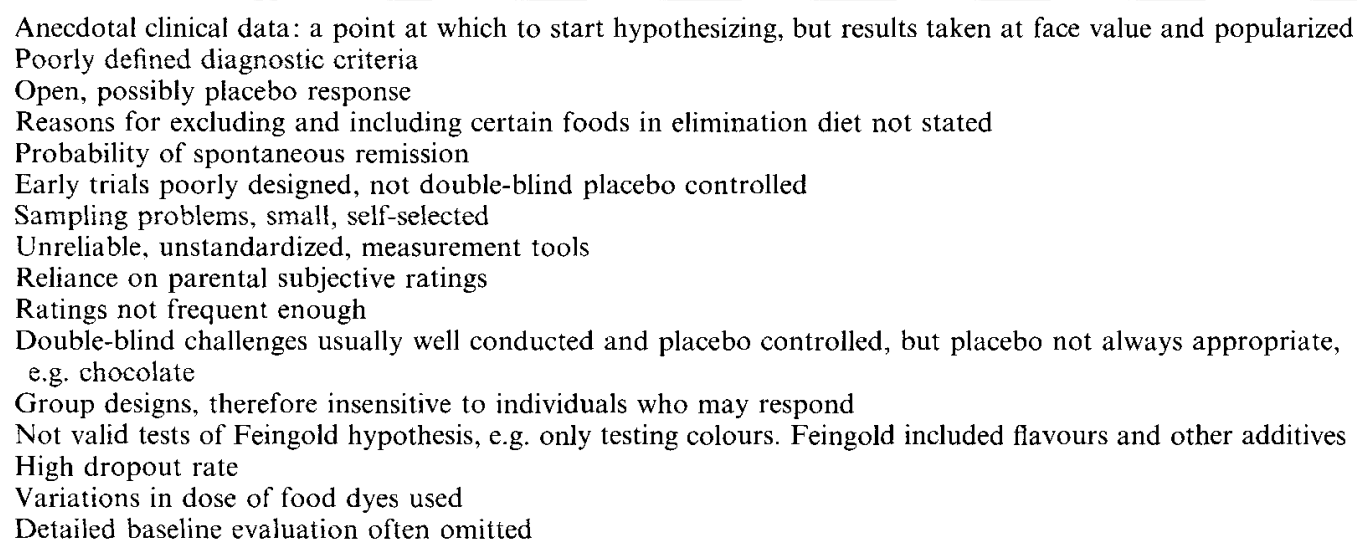

idiosyncratic reactions and hypersensitivity, either IgE- or non-IgE-mediated, could also cause the findings.

On the general use of the 'defined diets', the panel suggested that "the defined diets should not be universally used in the treatment of childhood hyperactivity at this time". If the general practitioner and the family felt that it was warranted, dietary intervention could be initiated, but not to the exclusion of other more traditional therapies, and proper evaluation would be needed. The panel also recommended changes in the law with regard to the labelling of foods.

\section{ANALYSES OF REQUIRED METHODOLOGY}

One of the main objectives of this review is to highlight the difficulties in design of studies in this subject, and to show that many of the published papers, whether for or against a food-behaviour link, have major methodological flaws. Thus, ten years after the Consensus statement, the same criticisms and questions must still be raised.

There are many problems with the published studies on hyperkinetic disorders (Table 3 ). In a critical but constructive paper, Dews (1983) commented on some major methodological issues. He pointed out that the field of study was now multidisciplinary in character. Investigators need competence in nutrition, metabolism, neurochemistry and behaviour. They must measure subjective phenomena that are affected by foods, and recognize that food and nutrient effects will more readily be demonstrated when behaviours have been perturbed than when they are already optimal. "Dose-effect studies... are essential... whether the compound being tested is a nutrient (or food) or - as is more commonly the case - a drug." Experimental design should be directed towards quantifying dose-effect relationships.

Silbergeld \& Anderson (1982) recognized many difficulties in dietary studies, for example in controlling children's eating behaviour between school and home and the fact that studies are not truly double-blind if there are changes in food preparation and consumption. They discussed reasons for discrepancies between double-blind crossover intervention studies and less controlled studies. Dietary effects may be very subtle; low success rates 
could be due to dietary infractions not noted by the investigators during test periods, and intervals between periods on test material and control may be too short, so that there is a carry-over effect.

Other significant issues are involved in the diet-behaviour research. Prinz (1985) criticizes the heterogeneity of subject samples, with respect to age, diagnosis and severity of behaviour problems. As diet seems to have varying effects depending on the age of the children, he questioned the wide age ranges in some samples. Often the children would also exhibit a wide range of problems of varying severity. Children from various diagnostic categories were sometimes included in the same sample, e.g. ADHD, anxiety disorders, learning disabilities, conduct disorders. Prinz questions the effect of multiple dietary influences on behaviour. Substances like colours, caffeine, etc. occur naturally together, yet dietary studies have usually isolated dietary components, not taking into account the combined impact of all dietary aspects. He recommended, that "during the next decade investigators will need to specify which dietary substances affect what behaviours, to what extent, and what conditions in which children".

\section{THE RANGE OF METHODS USED IN THE STUDY OF BEHAVIOUR AND FOODS}

It is pertinent to review some of the approaches used by investigators in the light of these comments.

\section{Case mix}

Clinical observations of highly selected, small groups of patients in uncontrolled environments are open to criticism of self-selected samples, placebo effect, and the possibility of spontaneous remission over time.

Feingold based his theories on patients presenting themselves to allergy clinics. Since then, data have been compiled on apparently normal children, retarded children, children with primary learning disorders, children whose parents feel that they fidget unduly, children whose parents have found, before the study begins, that they behave better when on a Feingold diet, cases referred with suspected hyperactivity to psychology or food allergy clinics, and overtly active schoolboys recruited by a letter sent to parents.

In some instances, clear differences from Feingold's patients emerge where objective measures of behaviour are reported. For example, in the study of active schoolboys recruited by letter, Conners' score was applied and only very small numbers of the subjects studied had a high score, diagnostic of ADHD (Kaplan et al. 1989).

\section{Types of elimination diet}

Many reports have simply compared normal and Feingold diets, on an open basis. Dietary intervention will be a dramatic event in the life of a family, and results could be due to many factors other than the test diet. Another approach is for the child's complete food requirement to be provided by the experimenters for a period of time. Thus, specially provided diets can be prepared which omit or include substances of interest such as additives and caffeine (Kaplan et al. 1989). By analogy with the regimen used to study multisystem reactions of food intolerance, yet another approach is to monitor behaviour before and after introduction of an oligoantigenic diet, which contains only one or two meats, one or two fruits or vegetables, salt, water and a simple margarine.

Techniques used to measure effects of the altered diet include simple teacher or parent ratings as well as a wide range of psychological tests. 


\section{Approaches to the use of challenges}

In many instances open challenge is used either initially or as the only test strategy. The ideal is the double-blind placebo controlled challenge in which the food substance to be tested is masked either in capsules or in a food which the patient is known to tolerate. The challenge material has varied considerably in different studies: a single substance such as tartrazine, given in capsules; a mixture of additives, with colours and flavours masked by an appropriate vehicle (this creates problems because the vehicle, e.g. a chocolate cookie, might itself contain substances to which the child can react). Other studies have used ordinary foods introduced as standard portions at intervals of a day or a week.

An alternative approach is to compare the behaviour of children who have been prescribed a Feingold diet, but who are known to have many diet infractions, with diet compliant children (Adams, 1981).

\section{STUDIES AND TRIALS OF DIET AND HYPERKINETIC DISORDERS}

\section{STUDIES BASED ON OBSERVATION}

There are many descriptive reports of associations between the K-P diet or its modifications and improvements in behaviour (see e.g. Thiessen \& Mills, 1975; Rapp, 1978; Swanson \& Kinsbourne, 1980; Holborow et al. 1981; Mattes \& Gittelman, 1981; Rogers \& Hughes, 1981; Hughes et al. 1982; Wender, 1986). Flaws and inconsistencies are evident in many of these reports, but some are convincing, although their positive results were usually obtained in a minority of cases examined.

Large, personal and anecdotal series tend to give high rates of reported responders to diet with positive open challenges, and implicate substances other than colourings. For example, Crook (1980) reported that 41 of 164 children gave an excellent, and 60 a good response to diet. Menzies (1984) described his case load over one year, claiming that $40 \%$ of his patients had 'allergic tension fatigue syndrome' and responded to diet.

An example of overinterpretation of objective data is provided by the work of Levy et al. (1978), who studied the effects of the Feingold diet, and of a 2-week tartrazine challenge, on hyperkinetic children. Behaviour was monitored by using the Conners' parent/teacher questionnaire. Neither significant improvement on diet nor relapse on challenge was recorded by teachers, but parents recorded behaviour improvement associated with the diet. There was no statistically significant effect of tartrazine challenge on behaviour as rated by mothers or teachers, or by psychologists and psychiatrists, who used various objective tests. Despite this, the authors claimed a significant effect, since a subgroup of children on the diet had shown a $25 \%$ reduction of symptoms on the Conners rating scale and had a statistically significant challenge effect at $P<0.025$.

\section{KEY WORK OF CONNERS}

In the 1970s and early ' 80 s, Conners undertook a series of studies assessing the effects of artificial colours on the behaviour of hyperactive children (Conners \& Goyette, 1976; Conners et al. 1976, 1980; Conners, 1980, 1981, 1989). These illustrate very well how, even when conducted by a sound and experienced clinical investigator, positive results in open studies cannot be reproduced with the same frequency in blinded challenge experiments, where placebo effects have been reduced or eliminated.

In the first study, 15 carefully selected children were observed for a baseline period of one month, then randomly assigned to a one-month control diet followed by an experimental 
diet or vice versa. Behavioural ratings (Conners' ASQ) were collected weekly from parents and teachers. Results were significantly positive in favour of the experimental diet, although there was an influence of diet order.

A second set of studies included a double-blind, crossover two-week challenge phase (Goyette et al. 1978). Chocolate cookies were used, either containing $13 \mathrm{mg}$ of artificial colours (active cookie) or no artificial colours at all, and 16 children were observed. Ratings were completed by parents and teachers, and scores remained low during the experimental period. However, an objective test of attention, the visual motor tracking task, suggested a transient (approximately $1 \mathrm{~h}$ ) effect of the artificial colours on the behaviour of these children, possibly by a pharmacological mechanism. The differences from control did not reach statistical significance.

The next trial had a similar protocol. A two-week baseline period was followed by a three-week Feingold diet period, and children who showed a $25 \%$ improvement of behaviour proceeded to further testing. Daily parental ratings were made within a $3 \mathrm{~h}$ period after the child had eaten test or placebo cookies. Significant worsening of behaviour during the challenge period was recorded by parents $(P<0.025)$, with order of treatment having no effect.

The results of a third, larger but otherwise similar trial, were entirely negative. Of 92 children, 30 eventually completed the study and no statistically significant effects of challenge were found. It may be relevant that the baseline Conners scores of the children in this study were lower than those of children in previous trials.

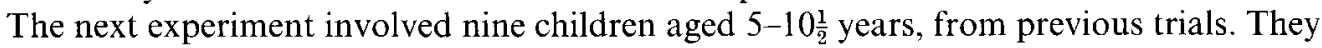
were screened by a child psychiatrist, and fulfilled strict criteria for attention deficit disorder. In previous studies eight of the nine had exhibited significant behavioural improvement in the non-blind dietary phase of trials. Children were on the Feingold diet throughout and had two challenge sessions. At each there was a baseline period for learning a task; activity measures were made, then the child ate two chocolate cookies, providing either $15 \mathrm{mg}$ artificial colours or placebo, double-blind. Learning tests (which had given positive results in earlier experiments) were performed over the next $3 \mathrm{~h}$, and activity and rating measures were also obtained. The test dose was half of the average daily intake of colours by adults, but might well have been a much lower proportion of the average intake of a child.

In these highly selected cases a transient acute effect of dyes was apparent on inspection of the data for some individual children, probably pharmacologically based. However, when results were combined and analysed by formal group statistics, no significant treatment effects were found for any of the dependent measures.

\section{RECENT STUDIES WITH MODERN TECHNIQUES}

There have been a number of recent studies of the food-behaviour link; selected, substantive reports are discussed below.

There have been few comparisons of the standard pharmacological therapy, stimulant medication, with diet. In a useful double-blind study Williams et al. (1978) tested 26 children aged 5-12 years judged to be responsive to stimulant medication. After a five-week K-P diet period, children followed a series of treatment conditions in sequence, which included their usual brand of medicine or placebo, and challenges with cookie containing artificial colours, or placebo cookie. Measures employed throughout the study included daily diet diaries and Conners' full rating scales by parents and teachers.

The effects of stimulant medication were statistically significant (parents and teachers), but the dietary effects were mixed. This study is limited in value by the sole use of 
behavioural checklists as outcome measures, the heterogeneity of the group, dietary infractions, short treatment periods and the fact that rating scales were not completed daily.

Gross (1984), in a camp setting, studied 18 children aged 11-18 years, diagnosed as hyperkinetic by a psychologist, and recruited from a private school for children with learning disorders. The experiment comprised a one-week K-P diet phase followed by a one-week experimental phase. Children were videotaped for $4 \mathrm{~min}$ at mealtimes and the behaviour rated by teachers who had not attended the camp. No difference was found between the two dietary phases. The authors noted that the K-P diet was difficult to adhere to as the children did not like it, and pointed out that there seemed little advantage in the diet since most hyperactive children respond well to medication. These results should be interpreted with caution, as there had been no baseline period, no objective outcome measures were used, the test period was very short and the setting was unrealistic.

Rowe (1988) selected, from 220 referrals, 45 boys (3-15 years) and 10 girls (3-11 years) for an open trial of the Feingold diet. The group was heterogeneous - some children, not particularly overactive or inattentive, were included in the trial at parental insistence. Each child had a full neurological examination and an electroencephalogram (EEG), and behaviour was assessed by trained observers and parent/teacher reports. Dietary infractions were noted. If there was no improvement, the diet was discontinued; if there was improvement, the diet was liberalized over a follow-up period of 3-6 months, and artificial additives were reintroduced. Fifteen $(27 \cdot 3 \%)$ showed no improvement on the K-P diet. Of the $40(72.7 \%)$ who improved, 26 remained so when the diet was discontinued, suggesting that the previous improvement in behaviour was due to a placebo effect of the diet.

In a second phase, 14 subjects who had shown stable improvement on the K-P diet over a period of at least 6 months continued the diet for 18 weeks and took a capsule with breakfast each day. These contained test substances $(50 \mathrm{mg}$ of carmoisine or tartrazine, or placebo) and were given for one week, several times, in random order. Daily behavioural checklists were completed by parents and (for some cases) by teachers. There were two significant responders to food colourings. A 7-year-old girl exhibited more activity, low frustration tolerance, sleeplessness and short attention span when receiving colourings $(P<0.01)$. She reacted within $2 \mathrm{~h}$ of ingesting the colours and the effect lasted for $34 \mathrm{~d}$. The second reactor was a 12-year-old boy, who showed similar problem behaviours including aggression $(P<0.05)$, and in whom it was 3.5 weeks after the last dose of colouring before his behaviour returned to prestudy levels. Both of these children were atopic, suffering from asthma and allergic rhinitis. The rest of the data in this study showed no relationship between diet and hyperactivity.

Pollock \& Warner (1990) evaluated 39 children aged 2.8-15 years whose parents had observed improvement in their behaviour when on a diet avoiding artificial additives, with deterioration after dietary infractions. They had been recruited from a paediatric clinic and a survey population. They mainly exhibited poor concentration and excess fidgeting. Of the 39 children, 19 completed a double-blind, placebo controlled trial, in which they took either a mixture $(125 \mathrm{mg})$ of artificial food colours or placebo of lactose, daily, in a gelatin capsule. There were two challenge and five placebo weeks. The 10-item Conners checklist and a 10-item somatic symptom questionnaire were completed daily by parents.

Mean daily behavioural scores were significantly higher in active weeks compared to placebo weeks $(P<0.01)$, whereas the somatic symptoms scores did not differ significantly between the two periods. The measurable (but small) change in behaviour scores was unrelated to changes in somatic symptoms or to atopic status of the children, and the authors suggest a pharmacological mechanism for this food additive intolerance. Most parents were unable to detect the effects of food colours on behaviour, and only two parents 
correctly identified all the challenge weeks. This is a most important point, since entry to the study had been based on parents' claims that they could detect children's behavioural changes when consuming additives.

Only two of the children studied would be considered to have ADHD on the basis of their Conners behaviour score, and so these results are likely to be more clinically relevant to general paediatric and allergy practice than to that of child psychiatrists. The study can be criticized for its sole use of parents as raters, the lack of objective outcome measures and the high dropout rate.

Egger et al. (1985) recruited 76 children from a clinic dedicated to the treatment of hyperactive children by means of diet. All had a score of more than 14 on the Conners ASQ. A high proportion had allergy, neurological disabilities and/or physical symptoms. They took an oligoantigenic diet for 4 weeks, and 62 children improved. Of these, 28 then participated in a double-blind, placebo controlled crossover trial. In a preliminary reintroduction phase, various foods, colourings and preservatives were tested by open introduction. If subjects reacted to particular foods these were withdrawn, otherwise the food was incorporated in the diet thereafter. Tartrazine and benzoic acid were each tested in doses of $150 \mathrm{mg}$ per day for one week.

During the next phase, reactions were tested to various active and placebo materials. Parents completed ASQ on a daily basis and a psychologist recorded behaviour. It was found that symptoms returned or worsened while the children took active substances as compared to placebos, although it should be noted that the reactions were mostly to artificial colourings and preservatives. The authors caution that the diet needs supervision, is difficult to maintain, could be used as punishment, and is dangerous nutritionally. The subjects in this study were not representative of all hyperactive children as they also had many associated symptoms. A further study has recently been conducted in the same institution, with essentially similar results (unpublished; personal communication, Dr S. Strobel).

\section{FOOD ADDICTION}

There are complex interactions between appetite, hunger, food likes and dislikes, and inappropriate or unbalanced eating behaviour. Individuals with psychological problems often have abnormal eating patterns and, as discussed above, there are theories of causative links between ingestion of particular foods and abnormal behaviour. Some proponents of these theories also suggest that in some circumstances where foods induce adverse physical or psychological reactions, the people affected become addicted to the provoking foodstuffs, thus sustaining the cycle of food sensitivity. For completeness, this somewhat incongruous idea must be considered in the context of this review.

\section{TOLERANCE, DEPENDENCE AND ADDICTION}

In the field of pharmacology, 'tolerance' refers to any situation in which repeated administration of the same dose of a drug results in gradually diminishing effects. Drugs and other pharmacologically active substances may have effects on several physiological systems, and an individual may become tolerant to only some of the multiple actions of a drug.

Physical dependence, or addiction, is the condition in which discontinuing the use of a drug leads to a characteristic set of symptoms called withdrawal.

Tolerance and dependence occur with the use of many stimulant substances, including not only drugs of abuse such as heroin, amphetamine and cocaine but also substances present in foods and beverages, and over-the-counter medications, such as caffeine and ephedrine. 
Table 4. Diseases due to caffeine consumption

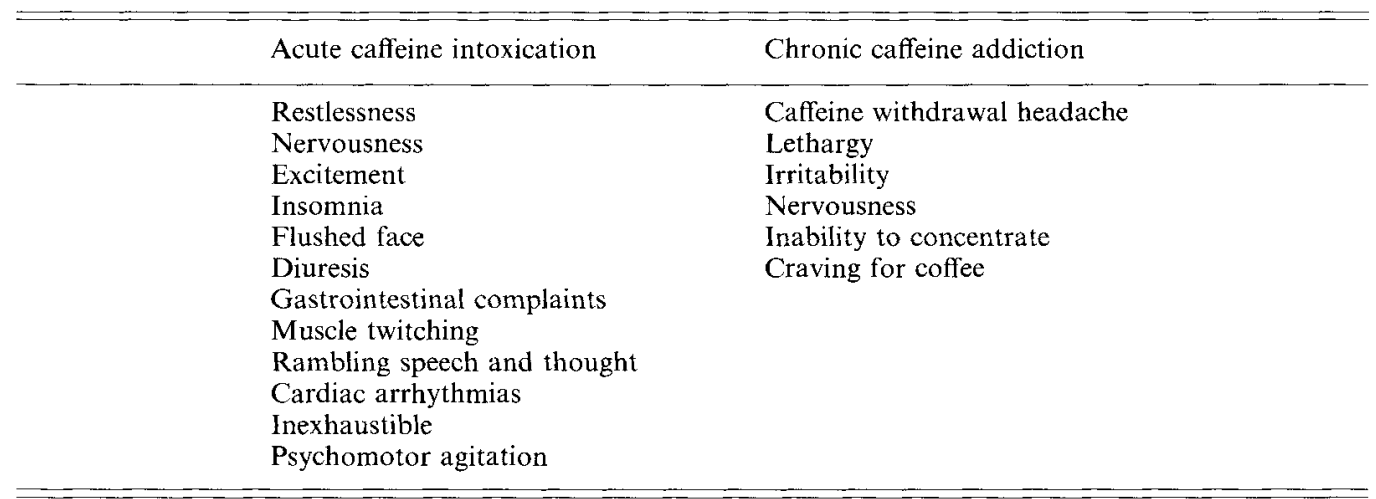

\section{THE EXAMPLE OF CAFFEINE}

Caffeine has been incriminated in two specific psychiatric diseases, acute intoxication from excessive consumption and chronic addiction from prolonged consumption (Table 4). Caffeine has potent pharmacological properties. It directly activates the cerebral cortex, but there is great interindividual variation in sensitivity to its desired stimulant effects maintaining wakefulness and improving concentration - and a minority of individuals are susceptible to the anxiety provoking effects of high doses (Kanarek \& Marks-Kaufman, 1991).

Even when taken in moderate doses, caffeine consumption may lead to physical dependence. Withdrawal produces a constellation of symptoms: headache, anxiety, depression, fatigue, listlessness, sleepiness, decreased alertness, and muscle tension (Kanarek \& Marks-Kaufman, 1991). The severity of withdrawal symptoms varies, and is directly related to the amount of caffeine ordinarily consumed.

\section{THE POSTULATED PHENOMENON OF FOOD ADDICTION}

Randolph \& Moss (1986) regard food allergy as one of the greatest health problems in the United States. They blame food allergy or addiction for ill health, particularly those "chronic, vaguely-defined problems which almost never respond to conventional treatment". Their views are based entirely on clinical observations which were first made in the 1940s. These authors have reviewed the development of the concept of "hidden addictions', i.e. that foods eaten frequently, three or more times per week, become substances of abuse and can cause health problems for the consumer. It is suggested that when the problem first develops, eating the food has a marked, immediate stimulating effect. If the affected individual avoids the relevant food, a kind of 'hangover' or withdrawal reaction occurs, which can be controlled by eating a further portion of the same food. Most specialists in conventional internal medicine or psychiatry disagree with these concepts.

\section{CARBOHYDRATE CRAVING}

People, rats, and many other animals have a specific hunger for carbohydrates - sweets and starches - that cannot be satisfied by eating any other kind of food (Wurtman, 1983). One theory is that the neurotransmitter serotonin turns off the hunger for carbohydrates, and 
that serotonin production, in turn, is affected by the amount of carbohydrate-rich food consumed.

\section{CHOCOHOLICS}

Chocoholics, or those addicted to chocolate, are surprisingly uniform in their insistence that the confection is habit forming, that it produces an immediate feeling of wellbeing, and that abstinence produces some of the symptoms of a withdrawal syndrome. Max (1989) discusses the properties of chocolate which may be relevant. These include the presence of pharmacologically active substances, histamine, tryptophan, serotonin, phenylethylamine and octopamine (although these exist in higher concentrations in other foods which do not have the same appeal). Theobromine, a methylxanthine, is present in cocoa and chocolate in very high amounts. However, milk chocolate contains less methylxanthines, and it is milk chocolate which is consumed most often by chocoholics.

\section{SACCHAROPHOBIA, HYPOGLYCAEMIA AND CRIMINAL BEHAVIOUR}

\section{DEFINITION}

Hypoglycaemia is defined by low circulating blood glucose levels $(<4 \mathrm{mmol} / \mathrm{l}$, $<500 \mathrm{mg} / \mathrm{l})$; clinically, this is usually accompanied by the symptoms of sweating, tremulousness, palpitations, anxiety, headaches, weakness and hunger; there is rapid amelioration of these symptoms when plasma glucose levels are returned to normal by the ingestion of food.

In clinical practice, hypoglycaemia is seen in insulin-dependent diabetic patients after exercise or when administration of insulin has not been balanced by an appropriate carbohydrate meal, in maturity-onset diabetics treated with oral hypoglycaemic drugs, in patients with rare insulin-secreting tumours, in some patients who have had radical gastric surgery, and in liver failure when there is inadequate synthesis of glucose by hepatocytes.

However, there have been many claims that hypoglycaemia, due to the presence of sugar in the diet, is a cause of chronic psychological problems including behaviour disorders. The explanation proposed is that excessive sugar intake actually causes rebound hypoglycaemia. The underlying assumption is that simple sugars are more quickly digested and absorbed than complex carbohydrates, so causing a greater increase in blood glucose levels, which stimulates insulin secretion. This leads to so-called functional or reactive hypoglycaemia (FH) (Kanarek \& Marks-Kaufman, 1991). It is this type of hypoglycaemia that is blamed for emotional problems, fatigue and irritability.

\section{CLAIMS FOR A LINK BETWEEN HYPOGLYCAEMIA, BEHAVIOUR DISORDERS AND PSYCHIATRIC DISEASE}

Pfeiffer (1975) stated that "a high incidence of FH is found in people with such disorders as schizophrenia, neurosis, alcoholism, drug addiction, juvenile delinquency, childhood hyperkinesis and obesity". In a similar vein, Fredericks (1976) claimed that "low blood sugar is capable of mimicking neurosis and psychosis". According to another authar, "medical experts in the field testify to the fact that this condition can have an amazing effect on behaviour, in some cases producing symptoms of lethargy and depression, and in other cases, irritability, suspiciousness, bizarre thoughts, hallucinations, extreme mania, anxiety, and violent behaviour. These persons are capable of such acts as stealing, rape, arson and homicide" (Hippchen, 1976). 


\section{CRIMINAL BEHAVIOUR, SUGAR AND HYPOGLYCAEMIA}

One of the most celebrated examples of society's negative views of sugar comes from the case of San Francisco city supervisor Dan White, who shot and killed the city's mayor and another city supervisor. White's lawyers argued that their client had acted irrationally and suffered from 'diminished mental capacity' as a result of his overconsumption of sugarcontaining 'junk' foods. On the basis of this argument, which has become known as the 'Twinkie defence', White was convicted of manslaughter rather than first degree murder (quoted from Kanarek \& Marks-Kaufman, 1991).

Virkkunen (1983) hypothesized that violent behaviour was caused by enhanced insulin secretion resulting from glucose intake. He claimed on the basis of symptoms and some oral glucose tolerance test (OGTT) data that individuals with a history of violent behaviour had more tendencies towards hypoglycaemia than controls, but this could not be taken as unequivocal evidence of an association between hypoglycaemia and antisocial behaviour. These studies did not correlate hypoglycaemia symptoms (sweating, hunger, tremors) with blood sugar levels. Also they presented no evidence of violent behaviour occurring when insulin secretion was enhanced or low blood sugar levels occurred. The reliability of OGTT data in detecting people who will have low blood glucose levels after ordinary meals is also questioned. It should also be pointed out that many of Virkkunen's subjects had a history of alcohol abuse.

\section{USE OF DIETARY CHANGES IN CRIMINAL INSTITUTIONS}

Schoenthaler (1986) carried out various dietary replacement studies with juvenile delinquents. The food policy in institutions was changed to reduce sugar consumption. Responses were measured according to the number of disciplinary actions taken by staff members before and after the change. Schoenthaler claimed a $21-54 \%$ reduction in antisocial behaviour of juvenile delinquents when their sugar consumption was reduced. Kanarek \& Marks-Kaufman (1991) point out that no sugar intake measurements were made in the studies, and there will have been other changes in nutrient composition of the diet. No attempt was made to blind the study; subjects and officials were aware of dietary changes. It seems likely that knowing they were taking part in this study may have led to changes in behaviour, and may have influenced staff, who used their own discretion when deciding when to record an incident.

Despite many criticisms of published reports, such as those of Gray (1986), who pointed out the inappropriate statistical methods used, the notion of an association between sugar and antisocial behaviour has been receiving increasing attention, and on the basis of these theories dietary policies have been changed in some correctional facilities in an attempt to control antisocial behaviour.

\section{EXTENSION OF THEORIES OF FOOD-CRIMINAL LINK TO OTHER FOODS}

Hippchen (1978) expressed the view that vitamin deficiencies or dependencies could cause perceptual changes, which in turn could produce altered behaviour, which might be criminal, but would seem appropriate to the individual. This alternative theory about the aetiology of antisocial behaviour has led to experimentation with megavitamin and nutritional therapies. 


\section{ANTHROPOLOGICAL STUDIES}

Bolton (1976) undertook a study of aggression and hypoglycaemia among the Qolla Indians of Peru. Social conflict could not be accounted for by social and cultural factors alone, so he explored the possibility that biological factors accounted for seemingly irrational aspects of behaviour. In the anthropological literature expressions such as 'aggression' and 'pervasive hostility' were used to describe the personality and behaviour traits of these people. Bolton reported a curvilinear relationship between the amount of drop in blood glucose during an OGTT and the level of aggressiveness of an individual in this population, and proposed that the relationship is causal in nature, with moderate glucose deprivation causing aggressiveness.

\section{RECENT CRITICISMS OF THE CONCEPT OF REACTIVE HY POGLYCAEMIA}

Kanarek \& Marks-Kaufman (1991) have critically discussed the causal hypothesis of sugar and hypoglycaemia. Their view is that a simple distinction cannot be made between blood glucose and insulin response to sugars and to more complex carbohydrates. Also the clinical symptoms described as hypoglycaemia are not consistently associated with low blood glucose levels. In much of this literature $\mathrm{FH}$ is diagnosed on the basis of symptoms alone. In their view, with which we concur, the condition of $\mathrm{FH}$ is quite rare. It has become popular because it is a respectable metabolic illness rather than a symptom of psychological distress. As is the case in other forms of psychologically based food sensitivity, people who complain of the symptoms of 'hypoglycaemia' should not be ignored, but should have proper clinical assessment and, if appropriate, psychological or psychiatric treatment.

\section{CONCLUSIONS AND RECOMMENDATIONS}

(1) There is an association between certain foods and hyperkinetic disorders, but only in a minority of affected children

Feingold based his hypothesis on the fact that changes in the diet of the nation had coincided with a rise in clinical referral rates of children with behaviour problems. His ideas generated much interest and considerable controversy, and this review of the literature on the subject confirms that there is indeed an effect of some foods on behaviour, but only in a minority of subjects properly studied. The effect is rarely profound, usually lasts only a few hours and probably has a pharmacological basis. Although most investigators have concentrated on food colourings, there are pharmacologically active constituents of many ordinary foods, and recent research (Strobel, unpublished) is revealing that foods such as milk and bread can also induce adverse behaviour effects in susceptible children.

There is a range of therapeutic options for the management of children with hyperactivity and minor behavioural problems. The evidence in the literature gives no support for the widespread application of either the Feingold diet, or more radical elimination diets, as primary therapy for these conditions, although there is no doubt that elimination diets are of benefit in some carefully selected and monitored children. In these circumstances, close attention must be paid to the nutritional balance of the diet. If vitamin and mineral supplements are prescribed, the formulations must be reviewed and preparations selected which do not contain potentially harmful colours or flavouring agents.

(2) Our review of the evidence does not support claims that food addiction and reactive hypoglycaemia are important factors in behaviour disorders and associated conditions 
Table 5. Requirements for adequate study of a postulated diet-behaviour link

1. Appropriate study design or within-subject design

2. Clear operational definitions

3. Clear diagnostic criteria

4. Sound sampling methods-size, age groups, gender, source

5. Control groups, matched, source defined, comparable characteristics

6. Instruments of measurement should be individualized, objective, observations recorded by using checklists, neuropsychological tests performed

7. Test environment defined: school, home, laboratory, hospital

8. Procedure: double-blind, crossover clinical trials; adequate baseline period; elimination diet;

then challenge, taking note that adequate dosage used; order effect considered; use colours, flavours, food per se; make allowances for time lapse, long term effects

9. Results analysed by use of appropriate statistical testing

10. Completeness, compliance, dropout, recorded; missing data accounted for

11. Distorting influences, extraneous treatments, changeover time, distortion by analysis, should be noted

(3) When further research is undertaken, this should be conducted by a multidisciplinary team, and natural foods as well as additives should be assessed

A high standard should be demanded of research in this difficult subject in the 1990s. There should be clearly defined cases, proper and multiple measures of behaviour, specific food ingredients studied, effects of elimination diet documented, followed by double-blind, placebo controlled challenge studies (Table 5). Non-psychological forms of food sensitivity must also be considered.

(4) It must be recognized that adverse effects of foods on behaviour may be either a manifestation of (probably pharmacologically based) food intolerance, or they may be psychologically based (e.g. via suggestion or adverse conditioning)

Adverse reactions to ingested foods are associated with a wide variety of symptoms, syndromes and diseases. The terminology used in the UK is as follows:

Food intolerance or food sensitivity is a reproducible, unpleasant (i.e. adverse) reaction to a specific food or food ingredient, and is not psychologically based.

Food allergy or food hypersensitivity is a form of food intolerance where there is both a reproducible food intolerance and evidence of an abnormal immunological reaction to the food (mediated by antibody and/or by $\mathrm{T}$ lymphocytes).

Psychologically based food reactions (food aversions) comprise both psychological avoidance - when the subject avoids food for psychological reasons - and psychological intolerance, which is an unpleasant bodily reaction caused by emotions associated with the food rather than the food itself and which does not occur when the food is given in an unrecognizable form.

The food-brain interactions in patients with hyperkinetic disorders fall into two of these three categories. If psychological reactions occur even when the affected person cannot identify the type of food which has been given, i.e. in a double-blind situation, the diagnosis is of food sensitivity. There is no evidence for an immune aetiology in these patients, and so the term 'allergy' should never be used in this context. There are also subjects who react convincingly in open, but not in blinded tests, i.e. who have psychologically based reactions to foods, manifested as adverse behavioural or psychological symptoms and signs. Careful clinical studies in other situations have revealed that such reactions may be the result of suggestion (Ferguson, 1990), and adverse conditioning is another possible mechanism. 
Clearly, in addition to further pharmacological research, work is urgently required on the diagnostic criteria, causes and treatment of the psychologically based behavioural forms of food sensitivity.

\section{BIBLIOGRAPHY ON FOOD AND THE BRAIN}

An extensive bibliography of publications to 1991, with keywords, has been prepared; further information may be obtained from Professor Ferguson (Fax UK 0313432570 ).

We gratefully acknowledge support for this project from the Biscuit, Cake, Chocolate and Confectionery Alliance; we thank Dr S. Strobel for preliminary discussions on the approach to this review and associated bibliography, Miss H. Lightbody for assistance in typing of the manuscript, and the staff of the Western General Hospital library for their invaluable help and advice.

\section{REFERENCES}

Adams, W. (1981). Lack of behavioral effects from Feingold diet violations. Perceptual and Motor Skills $\mathbf{5 2}$ 307-313.

American Psychiatric Association (1987). Diagnostic and Statistical Manual of Mental Disorders: DSM-III-R, 3rd rev. edn. Washington, D.C.: American Psychiatric Association.

Arnold, L. (1976). Causes of hyperactivity and implications for prevention. School Psychology Review 5, $10-22$. Barsky, A. J. (1988). Worried Sick: Our Troubled Quest for Wellness, pp. 3-20. Boston, MA: Little \& Brown. Beall, J. G. (1973). Food additives and hyperactivity in children. Congressional Record No. S19736, 35401-35407.

Bolton, R. (1976). Aggression and hypoglycemia among the Qolla: a study in psychobiological anthropology. In Physiology of Aggression and Implications for Control: an Anthology of Readings, pp. 189-217 [K. E. Moyer, editor]. New York: Raven Press.

Cantwell, D. P. (1975). Natural history and prognosis in the hyperactive child syndrome. In The Hyperactive Child: Diagnosis, Management, Current Research, pp. 51-64 [D. P. Cantwell, editor]. New York: Spectrum Publications Inc.

Clarke, T. W. (1950). The relation of allergy to character problems in children. Annals of Allergy $\mathbf{8}, 175$.

Conners, C. K. (1980). Food Additives and Hyperactive Children. New York: Plenum Press.

Conners, C. K. (1981). Artificial colors in the diet and disruptive behaviour: current status of research. In Nutrition and Behavior, pp. 137-143 [S. A. Miller, editor]. Philadelphia, PA: Franklin Institute Press.

Conners, C. K. (1989). Feeding the Brain: How Foods Affect Children. New York: Plenum Press.

Conners, C. K. \& Goyette, C. H. (1976). Progress Report of Studies on Hyperkinesis and Food Additives. Paper presented at Annual Meeting of the Food and Nuturition Liaison Committee. Naples: Nutrition Foundation.

Conners, C., Goyette, C. H. \& Newman, E. B. (1980). Dose-time effect of artificial colors in hyperactive children. Journal of Learning Difficulties 13, 512-516.

Conners, C. K., Goyette, C. H., Southwick, D. A., Lees, J. M. \& Andrulonis, P. A. (1976). Food additives and hyperkinesis - controlled double-blind experiment. Pediatrics 58, 154-166.

Crook, W. G. (1980). Can what a child eats make him dull, stupid or hyperactive? Journal of Learning Disabilities 13, 281-286.

Davison, H. M. (1950). The relation of allergy to character problems in children. Annals of Allergy $8,175$.

Dees, S. C. (1954). Neurologic allergy in childhood. Pediatric Clinics of North America 1, 1017-1027.

Dews, P. B. (1983). Comments on some major methodological issues affecting diagnosis of the behavioral effects of foods and nutrients. Journal of Psychiatric Research 17, 223-225.

Egger, J., Carter, C. M., Graham, P. J., Gumley, D. \& Soothill, J. F. (1985). Controlled trial of oligoantigenic treatment in the hyperkinetic syndrome. Lancet i, 540-545.

Feingold, B. F. (1976). Hyperkinesis and learning disabilities linked to the ingestion of artificial food colors and flavors. Journal of Learning Disabilities 9, 551-559.

Ferguson, A. (1990). Food sensitivity or self-deception? New England Journal of Medicine 323, 476-478,

Franklin, A. J. (1988). Hyperactivity - an allergic disorder? In The Recognition and Management of Food Allergy in Children, pp. 49-57 [A. J. Franklin, editor]. Lancaster: Parthenon.

Fredericks, C. (1976). Psycho-nutrition. New York: Grosset \& Dunlap.

Goyette, C. H., Conners, C. K., Patti, T. A. \& Curtis, L. E. (1978). Effects of artificial colors on hyperactive children: a double-blind challenge study. Psychopharmacology Bulletin 14, 39-40.

Gray, G. E. (1986). Diet, crime and delinquency: a critique. Nutrition Reviews 44 (Suppl.), 89-94.

Gross, M. D. (1984). Effect of sucrose on hyperkinetic children. Pediatrics 74, 876-878. 
Harley, J. P., Ray, R. S., Tomasi, L., Eichman, P. L., Matthews, C. G., Chun, R., Cleeland, C. S. \& Traisman, E. (1978). Hyperkinesis and food additives: testing the Feingold hypothesis. Pediatrics 61, 818-828.

Hechtman, L., Weiss, G., Finklestein, J., Werner, A. \& Benn, R. (1976). Hyperactives as young adults: preliminary report. Canadian Medical Association Journal 115, 625-630.

Hippchen, L. J. (1976). Biochemical approaches to offender rehabilitation. Offender Rehabilitation 1, $115-123$.

Hippchen, L. J. (1978). The Ecologic-Biochemical Approaches to Treatment of Delinquents and Criminals. New York: Van Nostrand Reinhold.

Holborow, P., Elkins, J. \& Berry, P. (1981). The effect of the Feingold diet on 'normal' school children. Journal of Learning Disabilities 14, $143-147$.

Hughes, E. C., Weinstein, R. C., Gott, P. S., Binggeli, R. \& Whitaker, K. L. (1982). Food sensitivity in attention deficit disorder with hyperactivity (ADD/HA) - a procedure for differential diagnosis. Annals of Allergy 49, 276-280.

Kanarek, R. B. \& Marks-Kaufman, R. (1991). Nutrition and Behavior: New Perspectives. New York: Van Nostrand Reinhold.

Kaplan, B. J., McNicol, J., Conte, R. A. \& Moghadam, H. K. (1989). Dietary replacement in preschool-aged hyperactive boys. Pediatrics $\mathbf{8 3}, 7-17$.

Leung, P. W. \& Luk, S. L. (1988). Differences in attention control between 'clinic-observable' and 'reported' hyperactivity: a preliminary report. Duchess of Kent Children's Hospital, Hong Kong. Child Care, Health and Development 14, 119-211.

Levy, F., Dumbrell, S., Hobbes, G., Ryan, M., Wilton, N. \& Woodhill, J. M. (1978). Hyperkinesis and diet: a double-blind crossover trial with a tartrazine challenge. Medical Journal of Australia 1, 61-64.

Mattes, J. A. \& Giltelman, R. (1981). Effects of artificial food colorings in children with hyperactive symptoms. Archives of General Psychiatry 38, 714-718.

Max, B. (1989). This and that: chocolate addiction, the dual pharmacogenetics of asparagus eaters, and the arithmetic of freedom. Trends in Pharmacological Sciences, 10, 390-393.

May, C. D. (1974). Food allergy. In Infant Nutrition, 2nd edn., pp. $435-459$ [S. J. Fomon, editor]. Philadelphia PA: W. B. Saunders Co.

Menzies, I. (1984). Allergic and immunological factors in child and family psychiatry. In Recent Research in Developmental Psychopathology (Journal of Child Psychology and Psychiatry, Book Supplement), pp. 95-109 [J. E. Stevenson, editor].

Mitchell, E. A., Aman, M. G., Turbott, S. H. \& Manku, M. (1987). Clinical characteristics and serum essential fatty acids in hyperactive children. Clinical Pediatrics 26, 406-411.

National Institutes of Health Consensus Development Panel (1983). National Institutes of Health consensus development conference statement: defined diets and childhood hyperactivity. American Journal of Clinical Nutrition 37, 161-165.

Pfeiffer, C. C. (1975). Mental and Elemental Nutrients: a Physician's Guide to Nutrition and Health Care. New Canaan, CT: Keats Publishing, Inc.

Pollock, I. \& Warner, J. O. (1990). Effect of artificial food colours on childhood behaviour. Archives of Disease in Childhood 65, 74-77.

Prendergast, M., Taylor, E., Rapoport, J. L., Bartko, J., Donnelly, M., Zametkin, A., Ahearn, M. B., Dunn, G. \& Wieselberg, H. M. (1988). The diagnosis of childhood hyperactivity: a U.S.-U.K. cross-national study of DSM-III and ICD-9. Journal of Child Psychology and Psychiatry 29, 289-300.

Prinz, R. J. (1985). Diet-behaviour research with children: methodological and substantive issues. Advances in Learning and Behavioral Disabilities 4, 181-199.

Randolph, T. G. (1945). Fatigue and weakness of allergic origin (allergic toxemia); to be differentiated from 'nervous fatigue' or neurasthenia. Annals of Allergy 3, $418-430$.

Randolph, T. G. (1947). Allergy as a causative factor of fatigue, irritability and behaviour problems of children. Journal of Pediatrics 31, 560-572.

Randolph, T. G. \& Moss, R. W. (1986). Allergies: Your Hidden Enemy, 4th edn., pp. 15-39, 101-108. Wellingborough: Thorsons Publishing Group.

Rapp, D. J. (1978). Does diet affect hyperactivity? Journal of Learning Disabilities 11, 383-389.

Rogers, G. S. \& Hughes, H. H. (1981). Dietary treatment of children with problematic activity level. Psychological Reports 48, 487-494.

Rostain, A. L. (1991). Attention deficit disorders in children and adolescents. Pediatric Clinics of North America 38, 607-635.

Rowe, K. S. (1988). Synthetic food colourings and 'hyperactivity': a double-blind crossover study. Australian Paediatric Journal 24, $143-147$.

Rutter, M. (1989). Child psychiatric disorders in ICD-10. Journal of Child Psychology and Psychiatry, 30, $499-513$. Schoenthaler, S. J. (1985). Nutritional policies and institutional antisocial behaviour. Nutrition Today 20, 16-25.

Shannon. W. R. (1922). Neuropathic manifestations in infants and children as a result of anaphylactic reaction to foods contained in their dietary. American Journal of Diseases of Children 24, 89-94.

Silbergeld, E. K. \& Anderson, S. M. (1982). Artificial food colors and childhood behavior disorders. Bulletin of the New York Academy of Medicine 58, 275-295.

Speer, F. (1954). The allergic-tension-fatigue syndrome. Pediatric Clinics of North America 1, $1029-1037$. 
Swanson, J. M. \& Kinsbourne, M. (1980). Artificial color and hyperactive behaviour. In Treatment of Hyperactive and Learning Disordered Children: Current Research, pp. 131-149 [R. M. Knights and D. J. Bakker, editors]. Baltimore, MD: University Park Press.

Taylor, E. A. (1986). Childhood hyperactivity. British Journal of Psychiatry 149, 562-573.

Taylor, E. A., Schachar, R., Thorley, G. \& Wieselberg, M. (1986). Conduct disorder and hyperactivity. I. Separation of hyperactivity and antisocial conduct in British child psychiatric patients. British Journal of Psychiatry 149, 760-767.

Thiessen, I. \& Mills, L. (1975). The use of megavitamin treatment in children with learning disabilities. Journal of Orthomolecular Psychiatry 4, 288-296.

Virkkunen, M. (1983). Insulin secretion during the glucose tolerance test in antisocial personality. British Journal of Psychiatry 142, 589-604.

Weiss, B. (1986). Food additives as a source of behavioral disturbances in children. Neurotoxicology 7, $197-208$.

Wender, E. H. (1986). The food additive-free diet in the treatment of behaviour disorders: a review. Journal of Developmental and Behavioral Pediatrics 7, 35-42.

Williams, J. I., Cram, D. M., Tausig, F. T. \& Webster, E. (1978). Relative effects of drugs and diet on hyperactive behaviors: an experimental study. Pediatrics 61, 811-817.

Williams, J. I. \& Cram, D. M. (1978). Diet in the management of hyperkinesis: a review of the tests of Feingold's hypotheses. Canadian Psychiatric Association Journal 23, 241-248.

World Health Organization (1990). ICD-10, draft of Chapter V: categories F00-F99, mental, behavioural and developmental disorders. Geneva: WHO.

Wurtman, J. J. (1983). The Carbohydrate Craver's Diet. Boston, MA: Houghton-Mifflin. 